\title{
LOS MICRORRELATOS DE CECILIA EUDAVE: IMPROBABLES MICROCOLAPSOS
}

\author{
Mari Sol Nava HernándeZ \\ Universidad Autónoma de Tlaxcala \\ marinav00@hotmail.com
}

Enviado: 14-06-2021

Aceptado: 25-08-2021

RESUMEN

La escritora mexicana Cecilia Eudave (1968) posee una obra sólida expuesta en ensayos, novelas, cuentos y microrrelatos. Estos últimos se encuentran principalmente en Para viajeros improbables (2011) y Microcolapsos (2017). De acuerdo con varios teóricos como David Roas, estos textos de Cecilia Eudave poseen las cualidades de la narratividad y brevedad, apoyados por rasgos formales (tramas sencillas, personajes con escasa descripción, espacio reducido o ausente, tiempo abreviado mediante la elipsis, pocos diálogos, final sorpresivo, títulos significativos y experimentación lingüística) y rasgos temáticos (intertextualidad e intención crítica). El objetivo de este trabajo es analizar las características discursivas, formales y temáticas de los microrrelatos de Eudave que confluyen en su propuesta estética; en ese sentido, al final nos enfocaremos en siete de sus mejores microrrelatos: «Vendas», «Hormigas», «La mascota imaginaria», «Cocodrilocabezas», «La amante del té», «Laberinto» $\mathrm{y}$ «De natura», los cuales devienen fantásticos, género al que la autora ha dedicado espléndidas páginas.

Palabras Clave: Cecilia Eudave; microrrelatos; rasgos; fantástico.

\section{THE MICRO-STORIES BY CECILIA EUDAVE: IMPROBABLE MICROCOLAPSES}

\section{ABSTRACT}

The Mexican writer Cecilia Eudave (1968) has a solid work exhibited in essays, novels, tales and micro-stories. The latter are mainly found in Para viajeros improbables (2011) and Microcolapsos (2017). According to several theorists such as David Roas, these texts 
by Cecilia Eudave possess the narrativity and briefness qualities, supported by formal features (simple plots, characters with little description, reduced or absent space, time shortened by ellipsis, few dialogues, surprising ending, meaningful titles and linguistic experimentation) and thematic features (inter textuality and critical intention). The aim of this work is to analyze the discursive, formal and thematic characteristics of Eudave's micro-stories that converge in her aesthetic proposal; in this sense, in the end we will focus on seven of her best short stories: «Vendas», «Hormigas», «La mascota imaginaria», «Cocodrilocabezas», «La amante del té», «Laberinto» and «De natura», all of which become fantastic, a genre to which the author has devoted splendid pages.

KeYwords: Cecilia Eudave; micro-stories; features; fantastic.

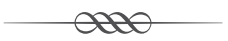

\section{PreÁmbulo}

El microrrelato, texto seductor y versátil, posee una larga tradición sostenida por escritores como Rubén Darío (1867-1916), Julio Torri (1889-1970), Jorge Luis Borges (1899-1986), Enrique Anderson-Imbert (1910-2000), Julio Cortázar (1914-1984), Edmundo Valadés (1915-1994), Juan José Arreola (19182001), Augusto Monterroso (1921-2003), Otto-Raúl González (1921-2007), Marco Denevi (1922-1998), Guillermo Cabrera Infante (1929-2005), José de la Colina (1934-2019), René Avilés Fabila (1940-2016), Guillermo Samperio (19482016), José María Merino (1941), Felipe Garrido (1942), Juan Armando Epple (1946) y Ana María Shua (1951), entre otros.

La vasta producción de microrrelatos ha originado múltiples y profundos estudios en torno a su definición y componentes estéticos. Así, para David Roas: «el microrrelato no es un género autónomo diferente del cuento, sino una de las vías por las que dicho género ha evolucionado desde el último tercio del siglo XIX» (2010: 38), idea considerada por teóricos precedentes como Violeta Rojo, para quien el microrrelato cumple «con los elementos básicos que debe tener un cuento» (1997: 15). En este mismo tenor, Javier Perucho considera que el microrrelato incluye «los elementos constitutivos de todo relato bien nacido» (2006: 31), dicho con otras palabras, «es una obra de ficción (...) que tiene como cometido inmediato, sometido a ciertas normas de composición, plantear un conflicto humano» (2009: 232). Domingo Ródenas de Moya resume estos planteamientos: «Para que un texto literario pueda ser considerado microrrelato sólo debe cum- 
plir dos condiciones: brevedad y narratividad» (2010: 185 sic), es decir, debe poseer elementos literarios narrativos y ser lacónico (Acosta Blanco, 2011: 79).

Con base en estas primeras delimitaciones, se establecen varios atributos de los microrrelatos, aunque no son exclusivos de estos, pues igualmente los hallamos en el cuento. David Roas, recuperando a autores como Francisca Noguerol o Irene Andrés-Suarez entre otros, compendia cuatro tipos de rasgos: discursivos, formales, temáticos y pragmáticos. Los discursivos implican narratividad, hiperbrevedad, concisión, intensidad expresiva, fragmentariedad e hibridez genérica (2010: 13). Los rasgos formales aluden a una trama sencilla, personajes con mínima caracterización, espacio reducido o ausente, tiempo abreviado mediante la elipsis, diálogos nulos o escasos, final sorpresivo, títulos significativos y experimentación lingüística. Los rasgos temáticos incluyen intertextualidad, metaficción, ironía (o recursos similares como la parodia o el humor) e intención crítica. Finalmente, los rasgos pragmáticos se centran en el lector, específicamente en su impacto y activa participación (2010: 14). Por supuesto, estos rasgos se actualizan en cada microrrelato, no se necesita la presencia de todos, solo los que el autor decide utilizar y priorizar en su texto (2010: 14).

A partir de este marco teórico, nos centraremos en los microrrelatos de la escritora mexicana Cecilia Eudave (1968), quien posee una amplia obra ${ }^{1}$ y estudios en torno a ella. No obstante, sus microrrelatos aún requieren análisis críticos, pues escasamente existe algún artículo académico o reseñas periodísticas sobre ellos; es el caso de la nota de Edilberto Aldán:

Los cuentos de Para viajeros improbables son efectivos representantes de la minificción, cada uno es la invitación a compartir el pacto ficcional, ofrecen las características esenciales del minicuento, más allá de su brevedad requieren de la intervención del lector para completarse, con su estructura proteica, convidan al juego a través de hallar el cuento bajo las características del ensayo, la poesía, el ensayo o los instructivos (2012: 7).

Nuestro objetivo consiste en analizar los textos reunidos en Para viajeros improbables (2011) y Microcolapsos (2019), ${ }^{2}$ con el fin de hallar los rasgos que los identifican como microrrelatos o microcolapsos improbables, parafraseando a los dos títulos y, de ese modo, distinguir las semejanzas y diferencias entre un libro y otro, es decir, el devenir estético de la autora respecto a su producción de microrrelatos.

1 La cual comprende ensayos, novelas, cuentos y, por supuesto, microrrelatos.

2 Este libro posee una primera edición, publicada en México en 2017, bajo el sello Editorial Paraíso Perdido. Para este trabajo consideramos la última y más reciente edición. 
De los cuatro rasgos recopilados por David Roas nos interesan tres: los discursivos, los formales y los temáticos. Eludimos los rasgos pragmáticos, pues son motivo de otro estudio que excede los límites del actual, en tanto nos interesa enfocarnos en el plano inmanente y textual. Determinar y analizar estos rasgos es inexcusable para una mejor comprensión de la poética eudaviana, pues como lo indica la propia autora durante su participación en el Primer Festival Internacional de Minificción 2021, el microrrelato es como un bonsái, es decir, un árbol en miniatura; de este modo, al ser un breve cuento posee espacio, tiempo, personajes y cuenta algo, son «universos bajo cero», «inteligentes»y «polisémicos» (Eudave, 2021); en este sentido, el estudio de sus rasgos evidencian estas virtudes.

En la última parte del trabajo examinaremos siete microrrelatos: «Vendas», «Hormigas», "La mascota imaginaria» y «Cocodrilocabezas» de Para viajeros improbables y «La amante del té», «Laberinto» $\mathrm{y}$ «De natura» de Microcolapsos, donde se observan todos los rasgos aludidos, así como recursos y temáticas inherentes a lo fantástico para lo cual recurrimos, principalmente, a la propuesta teórica de Rosalba Campra. Elegimos esos microrrelatos fantásticos porque consideramos que son los mejores exponentes de la producción y poética de Cecilia Eudave.

\section{RASGOS DISCURSIVOS, FORMALES Y TEMÁtICOS}

En primera instancia, los rasgos discursivos fundamentales en los microrrelatos de nuestra cuentista son la narratividad y la brevedad, los cuales resultan insoslayables para considerarlos como tales. Para viajeros improbables integra 37 microrrelatos y Microcolapsos, 21; este corpus ostenta una naturaleza narrativa, es decir, posee una historia, una trama, «una acción sustentada en un conflicto y en un cambio de situación y de tiempo, aunque sean mínimos» (Andrés-Suárez, 2010: 162). Para viajeros improbables incorpora una sección, «Países que debo visitar algún día», cuyos textos podrían parecer ajenos a la narratividad; sin embargo, la mayoría ${ }^{3}$ apela a una variación en la historia al incorporar acciones, elipsis y un conflicto: «Eudave nos introduce de este modo en el terreno de lo maravilloso, categoría que permea toda la sección por ofrecernos la imagen de mundos totalmente inventados, sin conflicto entre lo real e imposible, en los que tanto personajes como narrador y lector

3 Excepto «Otur: el país de los inexistentes» con sus visos claramente poéticos y alegóricos. 
asumen lo que ocurre sin cuestionarlo» (Noguerol, 2014: 65). De este modo, en «Tabi: el país de lo inestable», el narrador relata las fugaces y volubles acciones de sus habitantes, mientras que en «Obu: el país de los objetos» el narrador puntualiza el destino de aquel sitio: «Eran apenas un lunar en el mundo. Ahí estaban ricos y poderosos los obuenses. La envidia que desataban en el resto de los mortales no fue motivo de su extinción, sino la riqueza desmedida» (Eudave, 2011: 23). Dichos microrrelatos poseen una narratividad sutil, encubierta por las descripciones de estos países. Aunque alejados del tópico espacial maravilloso, hallamos una similar situación en «Cinco minutos», «¿Estás despierto?» o «Sobre el amor y otras cóleras» de Microcolapsos.

La brevedad es otro rasgo discursivo ineludible de los microrrelatos (Roas, 2010: 25) y los de Cecilia Eudave lo comprueban. Este atributo ha generado varias controversias, que van de las propuestas cuantitativas y rígidas a otras más flexibles. En las primeras ubicamos a Lauro Zavala, quien realiza una clasificación discutible: «Por debajo del límite de las 2000 palabras parece haber tres tipos de cuentos distintos entre sí: cortos (de 1000 a 2000 palabras), muy cortos (de 200 a 1000 palabras) y ultracortos (de 1 a 200 palabras)» (2006: 38). Irene Andrés-Suárez aporta una opción más moderada: «Sobre la extensión formal del microrrelato hay distintas opiniones, que van de un texto de pocas líneas, una página, hasta tres o cuatro páginas» (2010: 167), es decir, son textos que poseen una extensión reducida, anunciada por los prefijos «micro» $\mathrm{y}$ «mini» (2010: 162). Con una propuesta más certera, David Roas comenta que tienen «extensiones muy diferentes, que oscilan (...) entre página y media y siete páginas» (2010: 29). En todo caso, como apunta Violeta Rojo «Cualquier intento de establecer límites precisos a la longitud de un cuento es arbitrario y sobre todo artificial. Los minicuentos idealmente tienen una página impresa, o menos. Pero en realidad no pierden su condición porque sobrepasen este límite en algunas líneas» (1997: 66). Acertadamente, Javier Perucho confirma esta moción: «La extensión nunca puede suplantar por ningún motivo a la estética» (2006: 14), la cual sella cada línea de los microrrelatos eudavianos, construidos con la impronta de la brevedad. Así, los microrrelatos de Para viajeros improbables oscilan entre la media página («Sobre las ciudades invisibles») y las dos páginas y media («Cocodrilocabezas»); por su parte, los textos de Microcolapsos fluctúan entre media página («Al oído») hasta el más extenso de ambas colecciones con cuatro páginas («De natura»). Estos microrrelatos son breves y, en todo caso, apelan a la máxima de que «la brevedad de lo breve deberá mantenerse en el territorio flexible de la lógica difusa» (Ródenas de Moya, 2010: 186); en palabras de Cecilia Eudave, son textos que «logran decir mucho en tan poco» (2015). 
Con base en la narratividad y la brevedad, emergen los elementos formales. Los microrrelatos de Cecilia Eudave generalmente poseen tramas sencillas. «Martha y su bicéfalo», del primer libro, narra la necedad de la protagonista quien tiene como pareja a un bicéfalo; mas al complicarle la vida, decide cambiarlo por un troglodita; en «Recuerdos de una taza» (Microcolapsos), la trama se centra, como adelanta el título, en las memorias de una taza, cuyo fin es similar al de la amante de su dueño: «Me lanzó contra la pared, como a su última mujer, y como ella yo también me hice añicos» (Eudave, 2019: 39). Los narradores son parte fundamental de las tramas; al respecto, existe un cambio sustancial de un libro al otro: en Para viajeros improbables predominan los narradores externos, mientras que en Microcolapsos sobresalen los narradores-protagonistas, es decir, en el segundo libro los personajes expresan por sí mismos su conflicto.

Otro rasgo formal se halla en la escasa caracterización de los personajes, incluso a veces no está «definido, y ni siquiera nombrado, pero personaje al fin, [se ubica] en un espacio y en un tiempo» (Rojo, 1997: 44), es decir, son «actantes difuminados» (Fernández Pérez, 2010: 129), parcamente «perfilados» (Andrés-Suárez, 2010: 168). Es el caso de los astomos, personajes de «Un malentendido», descritos como «-los sin boca- son un pueblo tranquilo que vive — quedan pocos - mayoritariamente en las altas montañas de Europa y se alimentan de olores: es natural, no tienen boca» (Eudave, 2011: 35). Son pocos los microrrelatos de la autora que presentan pequeñas descripciones de los personajes, como sucede con los agripianos «seres con cabeza de pájaro y cuello retorcido sobre su cuerpo de humano, con unas piernas descomunales» (2011: 33) y cuya imagen se asemeja a los seres referidos en los bestiarios. En los microrrelatos de Eudave también aparecen personajes-tipo, connaturales a este tipo de textos (Roas, 2010: 14); estos personajes-tipo se vinculan con la intertextualidad establecida con los mitos; así, encontramos brevísimas descripciones de seres como la Medusa «la más bella de todas las mujeres de su comarca. Pero como la belleza no viene sola, también le tocó estar repleta de locura» (Eudave, 2011: 37); el minotauro, descrito como «una bestia» (2011: 50), o la esfinge referida ampliamente, pues el microrrelato explica el origen de sus heterogéneos rasgos.

Respecto al tiempo, surge un reiterado uso de la elipsis que «consiste en la eliminación de un lapso prolongado de tiempo. El microrrelato recurre a esta técnica para reducir al máximo la verborrea del texto» (Taha, 2010: 263). En los microrrelatos de Cecilia Eudave, la elipsis surge en varios textos. «Fantasmas» (Microcolapsos) comienza con un ejemplo: «Me pasé media vida cazando fantasmas» (2019: 25); similar situación se halla en «Sábanas blancas»: «Nos escogió blancas y ahora lucimos cetrinas. Con la tristeza, el olor a nuevo 
acogió un aroma a humedad y a naftalina. Se opacó el satinado y envejecimos junto a ella esperando» (2019: 35); otro paradigmático y descorazonador ejemplo lo hallamos en «Al oído»:

Te voy a contar un cuento, dice. En él cabe toda nuestra historia, acota. Voy a resumirla, sin preámbulos, sin nudos, sin desvíos, afirma. La puedes escuchar de pie o apoyando la cabeza sobre la pared como cuando deseas la proximidad de alguna esperanza, sugiere. O tal vez prefieras cerrar los ojos e imaginarla a tu modo, como siempre.

-Ya, cuéntala.

Se acerca a mi oído y resume nuestra vida en una palabra: ficción, mientras sus labios se alejan (2019: 52).

En vínculo con el tiempo, el espacio también se presenta como una «construcción esencializada, escasez (incluso ausencia) de descripciones, reducidas referencias a lugares concretos...» (Roas, 2010: 14). Si bien los microrrelatos de «Países que debo visitar algún día» dan la impresión de ser los idóneos para ilustrar esa elemental espacialización, recordemos lo mencionado en la narratividad, esto es, que son textos donde las situaciones y acciones prevalecen, aunque veladas con sutiles descripciones apegadas al canon de lo maravilloso; para puntualizarlo tenemos «Sertar: Base espacial para experimentos emocionales»: «Sobre la extensa superficie de un planeta localizado a unos 200 años luz de la tierra (...) esa masa inmensa recubierta por una tenue bruma gaseosa parecía un enorme cristal que respiraba acompasadamente, con una tranquilidad espantosa y única» (Eudave, 2011: 19), la descripción de ese asombroso país resulta breve y sublime.

Otro rasgo formal de los microrrelatos son los diálogos: escasos o incluso inexistentes. En Para viajeros improbables encontramos diálogos implícitos, no señalados por guiones, como en «SSean: el país miniatura»: «¿de qué sirve poseer un país tan minúsculo en el cual jamás podrían habitar? "Pues porque es mío, bueno, de los dos. Somos amos y soberanos de toda esta tierra y de la gente que la habita. Así que tú tranquilita, nada de heredar lo nuestro" ¿Lo nuestro? Pero si era suyo» (2011: 12); un diálogo semejante aparece en «Sobre dragones»: "“Hizo bien salir señorita. Ahora se va a poner bueno el espectáculo" (...) “Hizo bien en no menospreciar el poder de lo imaginario"» (2011: 47). Por supuesto, hay microrrelatos donde prevalecen los diálogos y, por tanto, se identifican con guiones, como acontece en «El verdadero origen de la esfinge» $\mathrm{y}$ «Cocodrilocabezas». Microcolapsos utiliza con mayor énfasis este rasgo formal, aunque la brevedad del texto se conserva; así, «Los observado- 
res», «Pistolas», «Los uroboros»y «Laberinto» exponen un frecuente y fundamental uso del diálogo, en tanto los personajes entablan una conversación que signa la trama.

Los finales sorpresivos o enigmáticos son importantes en los microrrelatos. En ese sentido, advertimos una modificación entre los finales de Para viajeros improbables y los de Microcolapsos. Los finales del primer libro resultan sorprendentes, sugestivos y humorísticos. De esta suerte, «Hui-Chii: el país de las cosas perdidas» presenta un final sugerente, supeditado a la trama y a una sutil ironía: «Además, traemos la soberbia de quien cree que sabe lo que busca, y así, nunca llegaremos a este país, ni por cielo ni por mar, ni por tierra, porque para habitarlo lo mejor es perderse» (2011: 22). Los finales sorpresivos hallan una muestra en «Sobre las ciudades invisibles», pues cuando el narrador por fin encuentra la tan anhelada ciudad invisible: «Entonces, hice lo que tenía que hacer: me di la vuelta y me marché de ahí para siempre, no fuera aquello cierto, y no tuviera ya un motivo de búsqueda en la vida...» (2011: 25). Un excelente final humorístico se ubica en el microrrelato erótico «Malos hábitos», donde la narradora cuenta los sobresaltos que, según ella, un íncubo le provoca todas las noches: «mi piel sudara en frío y se mojaran mis pensamientos» (2011: 53); por este motivo, un médico le aconseja adquirir mejores hábitos alimenticios, pues todo es producto de su desorden, sin embargo, la narradora concluye: «Pero como yo nunca he podido llevar a cabo ninguna rutina y a los médicos les creo lo mismo que a los curas, sigo con mi apetito insaciable antes de ir a dormir...» (2011: 53). Por su parte, Microcolapsos expone finales menos sorpresivos y humorísticos; de hecho, en varios microrrelatos prevalece un sutil desencanto con un tono ligeramente acerbo; es el caso de «Pistolas», cuya trama aborda el uso habitual de las armas anunciadas en el título y cuyo cierre evidencia este dejo funesto: «afuera a todos nos estaba esperando una bala perdida o voluntariosa» (2019: 44); análogo matiz se percibe en «Fantasmas», donde el final apela a los arrepentimientos personificados que siempre acechan al narrador: "yo soy uno de tus remordimientos al que nunca invitaste un trago en aquella cantina cerca de la escuela aun sabiendo que fingía beber por no traer dinero» (2019: 26).

En los microrrelatos, como en cualquier texto literario, todo es significativo, no solo los finales. En este tenor, los títulos, como elementos paratextuales, son trascendentes, pues «la posición preliminar de los títulos ante cuerpos textuales tan diminutos, dota a estos elementos de una riqueza de significación que es crucial para programar el comportamiento del lector y, por ende, para hacer viable el funcionamiento del texto como construcción literaria» (Fernández Pérez, 2010: 130). El primer punto a destacar en la obra de Eudave es la si- 
milar organización de sus dos libros, pues ambos presentan cuatro secciones, todas ellas subtituladas. Para viajeros improbables incluye los apartados «Países que debo visitar algún día», «Apócrifamente hablando», «Animales y prodigios para algún jardín» y «Un epílogo menos breve pero con luna de cocodrilos». Microcolapsos se conforma por «Intangibles realidades», «El desencanto sutil de las cosas», «¿Sentencias o advertencias?» y «De naturaleza insólita o imaginada». En sendos libros, los subtítulos de las secciones adelantan el contenido de los microrrelatos que las integran, desde los países inexistentes («Países que debo visitar algún día») hasta una suerte de bestiarios («Animales y prodigios para algún jardín» y «De naturaleza insólita o imaginada»). Asimismo, en el primer libro destacan los títulos con alguna referencia intertextual mítica («Sirenas de mercurio», «Ojos cíclopes», «Sirenas mudas», «El verdadero origen de la esfinge», «Minotauro sin laberinto», «Una quimera es una quimera»), lo cual desaparece en Microcolapsos, cuyos títulos remiten al contenido y la trama.

El último rasgo formal expuesto por los microrrelatos de Cecilia Eudave es la experimentación lingüística, efectuada mediante palabras inventadas, las cuales enfatizan su poética de lo improbable. Así, tenemos a los países inexistentes: Ssean, Kay, Otur, Elzir, Tabi, Estiepen, Sertar, Hui-Chii, Obú, Gripia; también seres insólitos: los agripianos y los astomos, todos referidos en Para viajeros improbables. Esta experimentación lingüística disminuye en $\mathrm{Mi}$ crocolapsos, pues solo se indican dos clases de seres extraordinarios: los Uroboros y los Wak-wak.

Por otra parte, los rasgos temáticos presentes en los microrrelatos de Cecilia Eudave son la intertextualidad y la intención crítica. La intertextualidad, como varios teóricos han demostrado, es un recurso socorrido en la narrativa breve. Violeta Rojo comenta: «el autor debe conseguir un tema tan conocido que no tenga que dar largas explicaciones, ni deba perder tiempo ubicando al lector. Sólo bastan las referencias, por lo general de la mitología griega y romana o a los personajes de las fábulas y de los cuentos de hadas. Es como si en casos como estos, se contara más con el horizonte de expectativa del lector» (1997: 83-84 sic). Para Francisca Noguerol, este rasgo es «reflejo del bagaje cultural del escritor y por el que se recupera la tradición literaria aunando el homenaje al pasado (pastiche) y la revisión satírica de éste (parodia)» (2010: 81). La intertextualidad, por tanto, apuntala la brevedad narrativa, en tanto permite «reducir el texto a su mínima expresión (...) en torno a los principios de la intertextualidad o relaboración de mitos, historias famosas, refundición de fábulas, de motivos y personajes de obras literarias universales, etc.» (Andrés-Suárez, 2010: 172). 
Los microrrelatos de Cecilia Eudave aluden en múltiples ocasiones a personajes de la mitología griega, así como a la propia literatura, trasluciendo sus mecanismos intertextuales. Para viajeros improbables integra varios personajes míticos: las Sirenas («Sirenas de mercurio» y «Sirenas mudas»), los Cíclopes («Ojos cíclopes»), Medusa («Deformando la historia»), las Moiras («Alta costura»), los Centauros («Doble naturaleza»), las Arpías («Habladurías»), la Esfinge («El verdadero origen de la Esfinge»), el Minotauro («Minotauro sin laberinto»), las Quimeras («Una quimera es una quimera») y las míticas ciudades de Troya y de la Atlántida («Un buen conocedor»). Microcolapsos solo integra un microrrelato de este tipo, «Laberinto», que alude al Minotauro. La autora muestra su preferencia por el Minotauro y las Sirenas al crear dos microrrelatos sobre cada uno de estos personajes. En particular, le interesan las seductoras sirenas, sumándose así a los muchos escritores que las han recuperado como protagonistas de sus ficciones: "desde Torri, con "A Circe", que inició en México la paráfrasis del episodio homérico, las sirenas han tenido eco (...) en Renán, el mismo Monterroso, Elizondo, Campos y muchos otros más, quienes a partir de este relato primigenio, han realizado sus variaciones tanto al tema, rejuveneciéndolo, como al símbolo, actualizándolo» (Perucho, 2009: 206). El aporte de Cecilia Eudave al tema se halla en «Sirenas de mercurio» con su aguda crítica social, al igual que con «Sirenas mudas», donde apela a su ineludible y fascinante esencia: «las sirenas, mudas o no, siguen enloqueciendo a los hombres...» (Eudave, 2011: 45).

Ahora bien, «Como sucederá en muchos de los microrrelatos, a menudo el autor invierte el mito o lo actualiza, tiñéndolo de una mirada irónica y desmitificadora» (Alonso Fernández, 2019: 96); es el caso de «Deformando la historia», donde se cuenta la auténtica historia de la bella y seductora Medusa: “"Si no fuera por las víboras te haría el ser más feliz de la Tierra, pues es a ti a quien amo". Luego los acompañaba a la puerta y los despedía para siempre. Entonces comenzó el mito: los hombres abatidos se iban con el corazón petrificado y roto» (Eudave, 2011: 37-38); algo similar acontece en «Habladurías», pues las Arpías defienden su insoslayable personalidad para concluir con humor e ironía: «Esto nos pasa por tragonas, porque nos gusta comer y beber, porque somos comunicativas, sociables y atentas. Ahora (...) cargamos la ingrata pena de ser unas mitoteras que blanden blasfemias por doquier. $Y$ hasta van a creer que nos gusta que a cierto tipo de mujeres — que no nos llegan ni en clase ni en gula- les llamen por nuestro nombre» (2011: 44). En este contexto, adquieren relevancia las palabras de Francisca Noguerol, quien menciona una revitalización de los mitos (1994: 203), en tanto «"desacralizan" 
las historias refrendadas por la tradición» (1994: 204). Revitalizar y desacralizar son dos objetivos importantes que confluyen en modernizar a los personajes míticos: «Algunos autores imaginan en sus textos cómo sería la vida de los seres mitológicos en los tiempos modernos, para satirizar el prosaísmo de nuestra época» (1994: 210); «Laberinto» lo ilustra, pues el citadino Minotauro termina asumiendo su angustiosa situación actual: «Y sí, me abordó la preocupación de sentirme viejo y sin laberinto donde guarecerme» (Eudave, 2019: 59). Para actualizar y desmitificar a los mitos, generalmente se recurre al humor: «En estas nuevas lecturas de los mitos el humor ocupa un papel fundamental, ya que despoja a la historia de solemnidad y contribuye al distanciamiento del lector»(Noguerol Jiménez, 1994: 212); en este sentido, «Doble naturaleza» resulta un microrrelato estupendo por su humor y picardía, pues moderniza a los lascivos centauros al emplazarlos en los carruseles de las ferias actuales: «En ese vaivén aparente esperaban con paciencia a que la jovencita más dulce, casta y buena subiera sobre su lomo biforme para seducirla sin que ella se diera cuenta. Y en la locura del círculo, cada vez más veloz, del carrusel, ante la vista de todos, las hacían suyas. Quizá por eso nunca entendieron los padres por qué sus niñas bajaban con el rubor en las mejillas y pidiendo dar otra vuelta en el carrusel...» (Eudave, 2011: 40).

El otro asunto intertextual presente en los microrrelatos de Cecilia Eudave es la literatura, «un tópico insoslayable para la comprensión del funcionamiento de los microcuentos» (Fernández Pérez, 2010: 146). Para viajeros improbables provee tres ejemplos. ${ }^{4} \mathrm{El}$ primero se localiza en «Ssean: el país miniatura» que inicia con una alusión al afamado cuento de Horacio Quiroga «El almohadón de plumas»: «Su luna de miel no fue un largo escalofrío, sino un prolongado grito» (Eudave, 2011: 11), donde se parafrasea el inicio del cuento quiroguiano para anticipar la brutal historia de Carlota y Marcial. El segundo caso se halla en «Sobre las ciudades invisibles» que, como bien identifica Francisca Noguerol, realiza un «homenaje desde su título al espléndido texto homónimo de Italo Calvino» (2014: 67); por supuesto, temáticamente apela a los países inexistentes. «El otro sueño de Gregorio Samsa» configura el tercer ejemplo; este microrrelato pertenece al rubro de los «basados en personajes literarios en los que en ocasiones se cambian los atributos que tradicionalmente tienen los caracteres» (Alonso Fernández, 2019: 97); así, en este microrrelato, Gregorio Samsa modifica su inicial actitud y acciones, distanciándose del célebre personaje kafkiano: «Cuando Gregorio abrió los ojos se descubrió humano otra vez, los cerró

4 Microcolapsos no posee ningún microrrelato con este asunto intertextual. 
y se negó a abrirlos» (Eudave, 2011: 68); esta medida se explica, pues «un hombre que tenía que levantarse a diario para ir a trabajar, para mantener a su penosa familia, le pareció la peor de las pesadillas» (2011: 68); por eso, decide permanecer cerrado de ojos hasta que su familia lo cree muerto: «Lo enterraron vivo. Pero seguro, desde ese sueño profundo del que ya no despertará, sonríe complacido de no volver a la rutina...» (2011: 68). En estos tres casos, la intertextualidad surge «a nivel temático (el mito y la leyenda, personajes y autores literarios) y también en el plano formal (el discurso fantástico, policiaco, etc.). A menudo las referencias intertextuales se tiñen de ironía, en una visión paródica o desmitificadora ante los discursos originales» (Alonso Fernández, 2019: 93), como sucede en estos casos.

Por otra parte, la intención crítica signa los microrrelatos de Cecilia Eudave; de hecho, este rasgo temático deviene constante, por lo que resulta decisivo en su propuesta estética. Francisca Noguerol ha estudiado Para viajeros improbables ponderando este atributo y plantea que existe una crítica «al cientifismo imperante en nuestra época (...) en "Sertar: base espacial para experimentos emocionales”» (2014: 69), en “"Obú: el país de los objetos” se descubre como una mordaz crítica de nuestra sociedad de consumo, donde las adquisiciones acaban por ahogar a los individuos» (2014: 69). También existe una firme intencionalidad crítica en varios de los microrrelatos con alusiones intertextuales míticas, en tanto «denuncian de nuevo la codicia y mezquindad humanas, mostrando la degradación a que han sido sometidos los seres míticos por parte de nuestras sociedades» (2014: 71); «Ojos cíclopes» lo demuestra, al narrar el fin de estos seres por detentar el poder del vaticinio en su único ojo:

Los hombres, que siempre aparecen para traer consigo ciertas calamidades (...) Comenzaron a desojar a estos apacibles seres. Luego les dio por disecar los ojos para usarlos como amuletos. Más tarde les aplicaron una capa de oro para incrustarlos en sus templos. Los encerraron en triángulos o los dejaron reposar sobre manos abiertas pintadas en las puertas de los santuarios (...) y así acabaron con la etnia de los cíclopes que se apagaron uno a uno con su lágrima roja, ciegos y de frente al futuro (2011: 31-32).

Si esta intencionalidad crítica emergía en Para viajeros improbables de forma destacada en Microcolapsos se magnifica, pues varios microrrelatos evidencian este tono crítico: «Fantasmas» y los remordimientos por el abandono; «Imágenes de utilería», con los espejos y el narcisismo; «Pistolas» y el incremento de la violencia o «El demonio del viernes», con los vicios humanos. Estos microrrelatos, entre muchos otros, denuncian diferentes problemáticas 
humanas, dejando su impronta entre sus breves líneas de aguda intencionalidad crítica, las cuales suscitan hondas reflexiones, siendo una de las principales «la dulce incomodidad de la existencia» (Ballester, 2017).

\section{LOS MICRORRELATOS FANTÁSTICOS}

Carmen Alemany Bay ha postulado lo «inusual» en la obra eudaviana, pues diversos textos de la autora mexicana evidencian «baremos no usuales, infrecuentes; pues no hay en sus discursos una intencionalidad explícitamente fantástica aunque sí la necesidad de acudir a otros parámetros que fluctúan en la franja que oscila entre lo real y lo insólito» (2016: 135); por supuesto, varios de los microrrelatos analizados ejemplifican esta posibilidad; no obstante, consideramos que algunos de los mejores microrrelatos de Cecilia Eudave son decididamente fantásticos por sus recursos discursivos y tematizaciones. En este sentido, Eudave es una escritora que ha demostrado un constante y auténtico interés por lo fantástico; muchas de sus obras pertenecen a este género y, por supuesto, sus microrrelatos no son la excepción. Incluso, Alemany Bay ha expuesto en diversas ocasiones la adhesión estética de la autora a lo fantástico: así, «a partir de Registro de imposibles sus temas se articulan en lo que hemos denominado "narrativa de lo inusual" lo cual no es óbice para que en otras publicaciones traslade su discurso hacia códigos propiamente fantásticos» (2016: 136). Idea que recalca en un estudio posterior: «podemos encontrar en la eudaviana relatos de clara urdimbre fantástica y otros que no lo son tanto» (Alemany, 2021: 46). Respecto a sus microrrelatos, Alemany Bay comenta: «es en las microficciones donde nuestra escritora hace un amplio uso de la llamada narrativa de lo insólito, pues en ellas se hace gala, en ocasiones, de una perfecta factura de corte fantástico» (2019: 11-12). Además de esta clara propensión a lo fantástico, recordemos que «Uno de los géneros preferidos de los escritores de microrrelatos es el fantástico. En muchos textos se produce la intrusión de un elemento inquietante y perturbador en la realidad, con la intención de cuestionar los parámetros con los que se mide» (Alonso Fernández, 2019: 98).

Con base en estos motivos, concluiremos nuestro trabajo analizando los rasgos discursivos, formales y temáticos presentes en siete de los mejores microrrelatos de Cecilia Eudave, así como los motivos y tematizaciones que ostentan para ser considerados fantásticos; nos referimos a «Vendas», «Hormigas», «La mascota imaginaria» y «Cocodrilocabezas», pertenecientes a Para 
viajeros improbables, y «La amante del té», «Laberinto» $\mathrm{y}$ «De natura», incluidos en Microcolapsos.

En «Vendas», el narrador es una momia quien nos relata, en un texto que ocupa una página, el despojo de su parca vestimenta y la subsecuente manera de recuperarla. En este microrrelato el espacio, los diálogos, la experimentación lingüística y la intertextualidad son nulos; no así la elipsis temporal que precisa la trama desde el inicio: «Mi reputación se ha visto mermada por un malentendido ancestral» (Eudave, 2011: 59). La intencionalidad crítica también es definitiva y se centra en dos tópicos: la guerra y la ambición humana por el poder; sobre el primer asunto, declara la momia: «Guerra cruel, absurda, sangrienta, terriblemente sangrienta, como todas las batallas» (2011: 59), que obedece al segundo tópico: «los bárbaros humanos que siguen enfrascados en su finita idea de gobernar el mundo cuando morirán sin remedio por alcanzar ese poder que los obsesiona, incluso antes de tenerlo» (2011: 59-60). Con base en esta diatriba, la momia relata el saqueo y posterior recuperación de sus vendas, momento en el cual irrumpe lo fantástico mediante el eje de oposición animado/inanimado, en una de las posibilidades referidas por Rosalba Campra: «la abolición —o la suspensión- de las fronteras entre la vida y la muerte» (2008: 44), pues la fenecida momia adquiere vida y enojada «me levanto de la tumba a recuperar lo mío. Luego, lo que era de esperarse, terror, espanto, paros cardiacos, gritos... todo eso que acompaña a lo inexplicable» (Eudave, 2011: 60), esto es, la momia asume su naturaleza fantástica y lo que provoca esto en los demás. El final adquiere un sutil tono humorístico: «mientras yo a mi paso voy recuperando mis vendas, porque la eternidad me puede encontrar fea, pero no desnuda...» (2011: 60). El título de este microrrelato resulta ser un paratexto importante, pues mediante una metonimia se alude al personaje medular y su conflicto: el despojo de las «Vendas» de la momia.

En «Hormigas» destaca una «línea existencial, de visos claramente arreolanos» (Noguerol, 2014: 76), además de una imaginación excepcional. Similar a «Vendas», el espacio, los diálogos, la experimentación lingüística y la intertextualidad en este microrrelato son inexistentes. La trama es sencilla, pues se narra una historia de odio y venganza: la animadversión que el grandulón de Simón siente hacia las hormigas y la revancha que éstas perpetran contra el tatuaje de Simón. En dos páginas, el narrador proporciona breves descripciones de los personajes; de Simón refiere su peculiaridad física y su desalmada personalidad: «Simón ve a todos pequeños porque él nació excesivamente grande. Así, con ese odio a lo minúsculo, se encargaba de exterminar aquello que no era digno de su tamaño. Y con esa insana manifestación 
de ser magno, desarrolló un profundo desprecio, sádico y cruel, hacia las hormigas» (Eudave, 2011: 65). Asimismo, describe su tatuaje de dragón: «Simón adoraba ese tatuaje, ese dragón marino de color verde tifón que se tatuó en Manzanillo» (2011: 66). En este microrrelato, la elipsis temporal sirve para abordar el pasado de Simón: «cuando trabajó en el puerto en sus años de juventud, cuando iba por el mundo sin anclar bien sus odios. Ese tatuaje le recordaba el mar, la aventura, los momentos más entrañables y felices, ese tatuaje era su pasado» (2011: 66). Lo fantástico irrumpe cuando las hormigas deciden vengarse de Simón por todas las muertes y atrocidades que les ha causado atacando su querido tatuaje y dándose así la oposición animado/ inanimado en otra de sus facetas: «imágenes creadas por el hombre, objetos inertes como estatuas o cuadros (y, más recientemente, fotografías, películas) que al animarse interfieren peligrosamente con el mundo que las ha plasmado» (Campra, 2008: 45); así, el dragón tatuado en la piel de Simón adquiere vida: «La bestia alada quiso defenderse lanzándoles fuego rojo que el primer grupo comenzó a devorar con rapidez. Después batió sus alas intentando alejar al segundo bando, que atacaba los flancos y comía intrépidamente sus plumas pálidas. Otras tantas, con astucia, se enfrentaron a la cabeza — que él movía inútilmente» (Eudave, 2011: 66). A esta animación se suma el eje de oposición humano/no humano, pues las hormigas adquieren sentimientos humanos como el rencor, la venganza y la planeación, acercándose a lo fabulístico (Campra, 2008: 56). Además, el acontecimiento fantástico se confirma mediante el motivo del objeto mediador, es decir, un «objeto cuya presencia en el texto da testimonio de la veracidad de los hechos fantásticos narrados» (Ceserani, 1999: 43), con lo cual se ratifica la transgresión fantástica y que, en este microrrelato, surge mediante la percepción de Simón: «Como entre sueños pudo distinguir cómo algunas cargaban a sus espaldas plumas color verde tifón o garras azules. Mientras otras llevaban a cuestas un ojo, un diente o un trozo de fuego» (Eudave, 2011: 67). El final de «Hormigas» deviene sorpresivo, pues «a Simón esa visión le pareció imposible y, negándola con la cabeza, se volvió a dormir...» (2011: 67); si el personaje duda y descarta lo insólito, el lector no lo hará, pues esa visión final confirma lo fantástico. El título de este microrrelato, por tanto, se centra en el personaje colectivo, antagónico de Simón: las diminutas hormigas que, en su deseo de venganza, motivan la transgresión fantástica, pues la naturaleza inanimada del tatuaje de dragón se altera y adquiere una realidad animada.

«La mascota imaginaria» es un microrrelato formidable por su riqueza imaginativa y estética, incluidos sus rasgos formales y temáticos. La narrado- 
ra, en página y media, recuerda su infancia marcada por la presencia de su mascota, un ser que todos catalogan de imaginaria; por ello, decide eliminarla, para arrepentirse años después. Como se adelanta en el título, el personaje relevante, y que además atesora el desafío fantástico, es esa mascota imaginaria; por eso la narradora se detiene en una amplia descripción de la misma: «era una criatura dulce, delicada y extremadamente inteligente - ella me enseñó a leer-, con un cuerpo esbelto color jacaranda, tan delgada que podía pasar por separador de libro (...) con su finísimas manos de dedos largos golpeaba el libro cuando me equivocaba en la lectura, o lanzaba un gritito agudo pero delicioso en caso de que invirtiera o cambiara una palabra» (2011: 69 sic); sus «enormes ojos verdes» (2011: 70) y su «cola de lagartija» (2011: 70) complementan su increíble imagen. Esta fiel compañera «Era genial, pero insistían en que era imaginaria» (2011: 69); por esta razón, la narradora decide encerrarla en una cajita y confinarla en su closet. En este momento, la elipsis temporal adquiere relevancia para el efecto final: «Escuché su llanto, creo que tres días o diez noches, ya no sé (...) Con el paso del tiempo cesó aquello y yo me fui olvidando del asunto. Hasta que años más tarde, estaría yo por partir a la universidad y haciendo limpieza de mi habitación, encontré la cajita en el fondo del armario» (2011: 70). Esta elipsis prepara el final sorpresivo vinculado con el objeto mediador, pues la narradora abre la caja y se encuentra con lo inesperado: «Al ver ese minúsculo esqueleto blanquecino, arcaico como hoja de un viejo volumen de historia natural, comprendí de golpe la certeza que intenté ocultar bajo las sábanas» (2011: 70). La evidencia de este insólito ser conduce al correlato concreto/no concreto, pues todo apunta a un ser creado por la imaginación de la protagonista, sin embargo, al final se comprueba su existencia (Campra, 2008: 45). Este microrrelato concluye con una innegable intencionalidad crítica, rayana a la moraleja: «las peores crueldades siempre se cometen por creer tan ciegamente en la razón de los otros...» (Eudave, 2011: 70). «La mascota imaginaria» es un microrrelato enternecedor por la inusual mascota, pero terrible por la fuerza de los prejuicios racionales que limitan al mundo, cegándolo ante seres o situaciones extraordinarias.

«Cocodrilocabezas», el último y el más extenso microrrelato (dos páginas y media) de Para viajeros improbables, narra «la escheriana pesadilla de una niña, en principio fascinada por los pequeños caimanes que salen de un rompecabezas y, al final, devorada por la feroz y única cabeza de cocodrilo que éstos saben conformar» (Noguerol, 2014: 76 sic). En este microrrelato, la exigua descripción de los personajes es fundamental; la protagonista es Margarita, una niña enferma, recluida en su recámara y postrada en su cama; asimis- 
mo, aparece otro enigmático personaje: «aquel hombre oscuro de aspecto escurridizo (...) aquel ser extraño que no conoce y le pareció sumamente flaco» (Eudave, 2011: 73), quien, sin decirle nada, le entrega a Margarita un rompecabezas. La identidad de este hombre resulta un misterio, un vacío de información, pues no se dice de dónde proviene ni se vuelve a hablar de él; sin embargo, provee el desafío fantástico. Los otros personajes son la madre de la niña y, por supuesto, los cocodrilos, quienes encarnan lo fantástico al exponer la oposición animado/inanimado, pues al principio los cocodrilos configuran un incompleto rompecabezas (le falta una pieza), pero después adquieren movimiento y vivacidad:

Son unos cocodrilos formando un círculo del que parecen salir de manera muy ordenada, casi militarmente, simulando una marcha colegial con su «uno, dos, uno, dos». Y de pronto los ojos de Margarita parecen deslizarse de sus órbitas: ¡los cocodrilos no parecen salir, están saliendo del rompecabezas! (...) Ahora bailan de dos en dos y algunos cantan. Margarita, con algo de temor, se atreve a tocar el lomo de uno de los pequeños cocodrilos; éste, al sentir el tibio contacto, le guiñe un ojo con coquetería (2011: 73-74).

En esta animación de lo inerte, los diálogos cobran importancia, pues Margarita y los cocodrilos entablan una conversación orientada a la transgresora incursión de lo fantástico:

— Todo es real cuando te fijas bien en ello — -le dice otro.

一Hablan!

-Oye, niña, ¿quieres que te hagamos un truco? Sólo trae un poco de leche (2011: 74 sic).

Los trucos realizados por los cocodrilos aprestan el inesperado y sorpresivo final, pues los reptiles forman una enorme cabeza de cocodrilo que «abre sus fauces y ¡zas!, se la traga sin ningún esfuerzo» (2011: 75); este siniestro final cierra magistralmente con la prueba del hecho fantástico: «Después caen sobre la cama, ahora sí, las trescientas piezas» (2011: 75); este objeto mediador deviene complejo, pues implica la animación del rompecabezas que, en su calidad de sujeto, devora a Margarita, quien desaparece y se transforma en la pieza faltante de aquel fantástico juego. Es así como el eje de oposición animado/inanimado se sostiene con otros motivos de lo fantástico tales como la inversión sujeto-objeto y la metamorfosis. "Cocodrilocabezas», como ha señalado Francisca Noguerol, ostenta un guiño intertex- 
tual al cuadro escheriano «Reptiles» por la animación implícita de los lagartos; en ese sentido, configura una ecfrasis al realizar una descripción de una obra plástica. Finalmente, el título es revelador porque mediante una experimentación lingüística, una crasis que fusiona tres palabras, la autora produce un juego léxico que resume los motivos temáticos del microrrelato: rompecabezas, cocodrilos y cabeza.

En cuanto a Microcolapsos, encontramos en «La amante del té» un narrador que personifica lo fantástico, pues es un ser extraordinario dado su carácter evanescente, casi rayano a la esencia del té, y quien devela la relación erótico-amorosa que mantiene con su amante. En página y media, este narrador refiere la reunión de su amada con sus invitados, la conversación entre ellos y solo menciona de él sus «vapores ámbar» (2019: 30), una sutil metáfora e indicio de su naturaleza fantástica; por tanto, es un narrador que elude las descripciones y enfatiza los pocos diálogos. La elipsis temporal es imprescindible, pues permite a los invitados resumir el tópico central del microrrelato: «Al que le dieron de comer chocolate murió a los ocho meses y su cuerpo mostraba un estado brutal de podredumbre interior; el que tenía dieta de café, apenas dos años después todos sus órganos quedaron abrasados, calcinados; y el que vivía de té, tras tres años se envolvió en tal delgadez, en tal estado de linterna, que casi se veía a través de él la claridad» (2019: 2930). El sugestivo final se relaciona con la prueba de ese ser extraordinario y además se tiñe de un delicado erotismo al insinuar los efectos producidos en su amada, quien «consiguió abandonar la escena bélica, instalada en su sala, para llegar a esa otra parte donde yo la esperaba en todas mis dimensiones. Se estremeció al tacto, en medio de ese pequeño caos, sin que nadie entendiera por qué se ruborizaba» (2019: 30). Ese sonrojo configura una tenue prueba de lo fantástico y de la existencia de ese ser al exteriorizar el efecto erótico provocado en la mujer. De acuerdo con la propuesta de Campra, «La amante del té» ejemplifica el correlato concreto/ no concreto:

Por «concreto» entiendo aquí todo lo que resulta sujeto a las leyes de la temporalidad y la espacialidad: ocupa un lugar en el espacio, tiene peso y volumen. Lo no concreto, en cambio, al carecer de materialidad, no está sujeto a estas leyes, carece de peso, volumen, etc. Mientras el primer término de la oposición aparece como el mundo dado, el orden de lo no concreto puede diversificarse en una serie de motivos: por ejemplo, el recuerdo, la imaginación (como proyecciones mentales voluntarias); el sueño, la alucinación (como proyecciones involuntarias) (2017: 41). 
Este ser, sin identificarse plenamente, es translúcido, un sueño corpóreo con el talante del té y cuyo título adelanta el conflicto del microrrelato, incluida su carga erótica.

«Laberinto» posee un título metonímico que alude al mito griego del Minotauro y su dédalo; por tanto, el mito es definitivo como rasgo intertextual de este microrrelato de página y media, centrado en una conversación entre el narrador con un amigo y enfocada en el anhelo del primero: la búsqueda de «el laberinto de los laberintos» (2019: 58). Dado su carácter de charla, el uso del diálogo es indispensable; como también lo es la descripción espacial del laberinto, efectuada mediante una serie de posibilidades, en tanto los hay «casuales, secundarios e intencionales; univiarios o pluriviarios; geométricos o irregulares; de esquema fijo o mixto; redondos, rectangulares o curvos; compactos o difusos; acéntricos, policéntricos, monocéntricos; bidimensionales o tridimensionales; ramificados o complejos» (2019: 58-59). El final deviene sorpresivo cuando el narrador revela su identidad: «Lo vi alejarse mientras una lluvia finísima inició su rutina nocturna mojando mi cornamenta» (2019: 59), es decir, mediante la sinécdoque basada en los cuernos, el narrador declara ser el Minotauro; esa cornamenta funge como objeto mediador y prueba su existencia. Así, «Laberinto» ostenta dos ejes de oposición como temáticas fantásticas: lo animado / inanimado (un mito se corporeiza), pero también humano/no humano, pues se difumina el límite entre lo mítico y lo humano (Campra, 2008: 56). Por último, destacamos el tono melancólico y angustiante implícito en las últimas palabras del narrador-Minotauro: «me abordó la preocupación de sentirme viejo y sin laberinto donde guarecerme» (Eudave, 2019: 59). Este microrrelato intertextual desmitifica y moderniza el mito del Minotauro al situarlo en un escenario actual, donde lo abruma la vejez y la soledad.

Finalmente, el microrrelato más extenso de los dos libros analizados es «De natura», pues en sus cuatro páginas, resume una larga historia anunciada en su título: la pasión por la naturaleza insólita que mantienen tío y sobrino quienes, pese a sus esfuerzos, no lograrán ver y disfrutar de esa flora fantástica que hacia el final se trasluce. El microrrelato consigna breves descripciones espaciales, las cuales aluden a los jardines e invernaderos del tío: «los árboles, el pasto y cierto tipo de enredaderas que demandaban mucho esfuerzo» (2019: 63). Respecto a los personajes, no existe descripción del tío, del que incluso desconocemos su nombre; en el caso del sobrino, se consigna una escueta descripción: «medio casanova, que a cambio de libros de botánica antigua y de ciertas semillas exóticas introducidas en el país de contrabando, le pedía flores» (2019: 
64). Será la inquietud del sobrino, refrendada por su tío, la que conduzca al hecho fantástico. En ese sentido, serán importantes los escasos diálogos establecidos entre ambos personajes, pues preparan el tema del microrrelato:

En una de sus visitas, el sobrino le preguntó si había leído el libro que le obsequió a cambio de una orquídea acuática de extraña belleza.

-Sí, mas no era una novela cuyo tema fueran las plantas.

-Lo sé, pero habla de la creación.

—Yo cuido de la naturaleza, no soy su creador (2019: 64).

Esa conversación confluye en la existencia de un extraordinario árbol, cuyo nombre implica una innovación lingüística, el Wak-wak, de donde «brotan seres parecidos a los varones (...) la isla china donde florecen (...) una planta cuyas hojas se parecían a la higuera» (2019: 64-65). Sorprendentemente, el sobrino ha conseguido semillas de ese árbol y se las entrega a su tío, quien las siembra y cuida meticulosamente durante cinco años para obtener el fantástico fruto. En esta fase, el microrrelato integra varias elipsis temporales; la primera además suma una bella descripción: «Pasaron los cinco años y el árbol cumplió con sus expectativas (...) En abril el cuerpo ya estaba formado, en mayo nació una hermosa cabeza de rostro impecable y durante junio creció hasta convertirse en una adolescente perfecta que se desprendió y cayó al suelo gritando "wak-wak". Abrió los ojos y le dedicó una mirada pura, dulce como las flores de su invernadero» (2019: 65); por desgracia, este hermoso ser muere, pero el tío no desiste e inicia otro intento que también resulta fallido. El microrrelato prepara su sorpresivo final con otra trascendental elipsis: «Una década más tarde falleció el tío rodeado de sus plantas y fue enterrado junto a una higuera de apariencia particular. Heredó su propiedad a una pareja extraña de piel aceituna» (2019: 66). La presencia de la higuera y de la pareja funcionan como indicios del hecho sobrenatural, es decir, del florecimiento de los wak-wak consignado al final: «Ahora nadie entra en el recinto, por instrucciones de los excéntricos dueños se debe conservar como un santuario, asegurando así que ahí se concentra lo mejor de la naturaleza. Por la noche, los vigilantes que custodian las entradas escuchan risas y palabras en un idioma ajeno, nadie sabe de dónde provienen, y si les preguntas solo responden: "Es la voz del paraíso"» (2019: 66). Este final se liga con el objeto mediador y evidencia la irrupción fantástica centrada en los wak-wak, pues no solo se menciona a la pareja, sino también un idioma exótico y el paraíso. Aunque este microrrelato integra rasgos del discurso maravilloso mediante la naturaleza insólita referida al inicio (árboles zoomorfos, corderos vegetales, 
árbol de ocas), pronto elude este discurso para adherirse a lo fantástico al enfatizar la improbabilidad y casi inexistencia de los wak-wak. Por eso, al final emerge lo sobrenatural mediante la oposición humano/no humano: «la contraposición entre humano / no humano se da también en el ámbito de lo animado, provocando deslizamientos entre lo humano, lo vegetal y lo animal» (Campra, 2008: 58), como acontece con los fantásticos wak-wak.

\section{Conclusiones}

Como hemos expuesto, los microrrelatos contenidos en Para viajeros improbables y Microcolapsos ostentan rasgos discursivos, formales y temáticos, enfatizándose su narratividad y brevedad. Con ello, Cecilia Eudave logra la brevedad narrativa requerida: «contar una historia con tan pocas palabras es una labor de expertos, de conocedores del lenguaje, de rigor extremo en el uso de las palabras» (Rojo, 1997: 69). Sus microrrelatos fantásticos innegablemente lo demuestran recurriendo al uso reiterado de categorías predicativas: animado/inanimado, concreto/no concreto, humano/no humano, según la propuesta de Rosalba Campra, además de incluir el seductor motivo del objeto mediador y prueba del acontecimiento fantástico.

Con base en este análisis y como conclusión, enfatizamos las diferencias entre los microrrelatos de Para viajeros improbables y Microcolapsos, pues como suele suceder con las trayectorias escriturales, percibimos cambios sustanciales de un libro a otro, exceptuando las similares estructuras de ambos libros (cuatro secciones subtituladas que congregan diversos microrrelatos). De este modo, en el primer libro predomina la experimentación lingüística, los guiños intertextuales a mitos y asuntos literarios, a lo cual se aúnan los narradores externos, quienes recurren al humor y evidencian una abundante imaginación adherida a la poética de lo maravilloso y de lo fantástico. En oposición, Microcolapsos presenta escasa experimentación lingüística e intertextualidad; asimismo, predominan los narradores-protagonistas, quienes se apartan del efusivo humor y, por el contrario, acentúan la intencionalidad crítica; en ese sentido, estos microrrelatos ostentan desenlaces con una fuerte dosis de desencanto que permea todo el libro. Así, los siete años de diferencia entre un libro y otro han matizado algunos rasgos y puesto en énfasis otros. Lo relevante de ese itinerario escritural de nuestra escritora es el resultado: todos sus microrrelatos exponen estructuras y recursos idóneos para su naturaleza breve, poseen temáticas seductoras y amplia imaginación, lo cual con- 
fluye en el disfrute estético del lector. Estas cualidades literarias corroboran la evidente creatividad y talento de Cecilia Eudave, una de las escritoras más importantes de habla hispana de los últimos años y cuyos improbables microcolapsos, sin duda alguna, lo demuestran.

BibLiografíA

Acosta Blanco, Ángel (2011): «Panorama extraliterario sobre el minicuento en los últimos veinte años (1988-2008) en México y otros países hispanohablantes», Ensayos de minificción, UNAM, México, pp. 79-95.

ÁlAmo Felices, Francisco (2010): «El microrrelato. Análisis, conformación y función de sus categorías narrativas», en David Roas (comp.), Poéticas del microrrelato, Arco/Libros, Madrid, pp. 209-229.

AldÁN, Edilberto (2012): «Cecilia acierta», La Jornada Aguascalientes, 1 de abril, p. 7, disponible en <https: / / issuu.com/jornadags / docs/lja01042012> [20-4-2021].

Alemany Bay, Carmen (2016): «Narrar lo inusual: Bestiaria vida de Cecilia Eudave y El animal sobre la piedra de Daniela Tarazona», Romance notes, 56 (1), pp. 131-141, <https: / / doi.org/10.1353/ rmc.2016.0013>

- (2016): «Bestiaria vida, de Cecilia Eudave: novela corta, novela de laberintos, novela de lo inusual», Revista de Literatura Mexicana Contemporánea, 23(68), pp. 103-118.

— (2019): «Prólogo», en Cecilia Eudave, Microcolapsos, Eolas, León.

- (2020): «Lo insólito y lo femenino en algunas narradoras latinoamericanas actuales», Hispamérica. Revista de literatura, 145, pp. 3-12.

- (2021): «El legado de Amparo Dávila en narradoras mexicanas actuales», Brumal. Revista de investigación sobre lo Fantástico, vol. IX, núm. 1, pp. 33-52, <https:/ / doi.org/10.5565/ rev/brumal.763>.

Alonso Fernández, Ana María (2019): «El microrrelato: una poética de la intertextualidad», Microtextualidades Revista Internacional de microrrelato y minificción, núm. 5, pp. 93-105, <https: / / doi.org/10.31921/ microtextualidades.n5a6>.

ANDRÉS-SuÁREZ, Irene (2010): «El microrrelato: caracterización y limitación del género» en David Roas (comp.), Poéticas del microrrelato, Arco/Libros, Madrid, pp. 155179.

BALLester, Ignacio (2017): «Microcolapsos: Cecilia Eudave», en Retales coloquiales (blog), 28 de junio, disponible en <http: / / otaler.blogspot.com/2017/06/ microcolapsos-cecilia-eudave.html\# more $>$ [28-7-2021].

CAMPra, Rosalba (2008): Territorios de la ficción. Lo fantástico, Renacimiento, Sevilla.

Ceserani, Remo (1999): Lo fantástico, Visor, Madrid.

Eudave, Cecilia (2011): Para viajeros improbables, Arlequín editorial, Guadalajara.

- (2015): «Entrevista», Micronopio. Una serie de César Navarrete, 19 de agosto, disponible en <https: / / www.youtube.com/ watch? $\mathrm{v}=\mathrm{hNhDVtSxRS8}>$ [3-5-2021].

— (2019): Microcolapsos, Eolas, León. 
- (2021): Primer Festival Internacional de Minificción, 30 de julio, disponible en https: / / www.facebook.com / watch / live / ?v=249713843661859\&ref=watch_permalink [11-8-2021]

FERNÁNDEZ PÉREZ, José Luis (2010): «Hacia la conformación de una matriz genérica para el microcuento», en David Roas (comp.), Poéticas del microrrelato, Arco/Libros, Madrid, pp. 122-153.

Noguerol, Francisca (1994): «Inversión de los mitos en el micro-relato hispanoamericano contemporáneo», en Luis María Gómez Canseco (ed.), Las formas del mito en las literaturas hispánicas del siglo xx, Universidad de Huelva, Huelva.

— (2010): «Micro-relato y posmodernidad: textos nuevos para un final de milenio», en David Roas (comp.), Poéticas del microrrelato, Arco/Libros, Madrid, pp. 77-100.

- (2014): «Heterocósmica en la minificción mexicana: El caso de Cecilia Eudave», en Javier Ordiz (ed.), Estrategias y figuraciones de lo insólito en la narrativa mexicana (siglos XIX-XXI), Peter Lang, Berna, pp. 59-79, <http:/ / dx.doi.org/10.3726/9783-0353-0647-7/ 12>.

Perucho, Javier (ed.) (2006): El cuento jibaro. Antología del microrrelato mexicano, Ficticia, México.

- (2009): Dinosaurios de papel. El cuento brevísimo en México, UNAM/ Ficticia, México.

RoAs, David (2010): «Sobre la esquiva naturaleza del microrrelato», en David Roas (comp.), Poéticas del microrrelato, Arco/Libros, Madrid, pp. 9-42.

RódenAS DE MOYA, Domingo (2010): «Consideraciones sobre la estética de lo mínimo», Poéticas del microrrelato, en David Roas (comp.), Poéticas del microrrelato, Arco/ Libros, Madrid, pp. 181-208.

Rojo, Violeta (1997): Breve manual para reconocer minicuentos, Universidad Autónoma Metropolitana Azcapotzalco, México.

- (2010): «El minicuento, ese (des)generado», Poéticas del microrrelato, en David Roas (comp.), Poéticas del microrrelato, Arco/Libros, Madrid, pp. 241-253.

TAHA, Ibrahim (2010): «La semiótica de las ficciones minimalistas: el género como sistema modelizador», en David Roas (comp.), Poéticas del microrrelato, Arco/Libros, Madrid, pp. 255-272.

ZAVALA, Lauro (2006): La minificción bajo el microscopio, Universidad Nacional Autónoma de México, México. 